\title{
KOMPOSISI KIMIA MINYAK ATSIRI DAUN CENGKEH DARI PROSES PENYULINGAN UAP
}

\author{
Jayanudin \\ Jurusan Teknik Kimia, Fakultas Teknik \\ Universitas Sultan Ageng Tirtayasa \\ Jalan Jendral Sudirman km.3 Cilegon 42435 \\ e-mail : jaya_hisyam@yahoo.com
}

\begin{abstract}
Abstrak
Minyak atsiri sangat dibutuhkan dalam berbagai industri seperti industri parfum, kosmetik, farmasi, industri makanan, dan minuman. Penelitian ini bertujuan untuk mengetahui komposisi kimia minyak atsiri daun cengkeh dari proses penyulingan uap menggunakan analisa GCMS. Daun cengkeh kering seberat 1,5 kg yang sudah bersih dari kotoran dimasukkan dalam ketel suling dan ditutup dengan rapat. Steam dari boiler dialirkan ke ketel suling dengan tekanan 0,5 barG, 1 barG dan 1,5 barG selama 5, 6 dan 7 jam. Campuran minyak dan air yang keluar dari kondenser ditampung dan diamkan selama 24 jam untuk memisahkan air dan minyak. Minyak daun cengkeh dimurnikan dengan bentonit $10 \%$ dari berat minyak pada suhu $50^{\circ} \mathrm{C}$ sambil diaduk selama $1 \mathrm{jam}$. Minyak daun cengkeh yang telah terpisah dari bentonit ditambahkan $\mathrm{Na}_{2} \mathrm{SO}_{4}$ anhidrat dan diamkan selama 15 menit kemudian pisahkan air dan $\mathrm{Na}_{2} \mathrm{SO}_{4}$ dalam minyak. Sampel dengan \% rendemen terbesar di analisa komposisi kimianya menggunakan GCMS. Berdasarkan hasil penelitian didapat rendemen terbesar adalah 1,84\% dengan kadar yaitu eugenol 65,03\% dan trans-caryophyllene $20.94 \%$.
\end{abstract}

Kata kunci : Daun cengkeh, Eugenol, Minyak atsiri, Penyulingan uap

\begin{abstract}
Essential oils are needed in various industries such as industrial perfumes, cosmetics, pharmaceuticals, food industry, and beverages. This study aims to determine the chemical composition of clove leaf essential oil from steam distillation process using GCMS. Dry clove leaves weighing $1.5 \mathrm{~kg}$ are included in the kettle flute and sealed properly. Steam from the boiler flows into the kettle with the pressure of 0.5 barG, 1 barG and 1.5 barG for 5,6 and 7 hours. Mixture oil and water out of the condenser are accommodated and let stand for 24 hours to separate water and oil. Clove leaf oil was purified with $10 \%$ bentonite by weight of oil at a temperature of $50^{\circ} \mathrm{C}$ with stirring for 1 hour. Clove leaf oil that has separated from bentonite added anhydrous $\mathrm{Na}_{2} \mathrm{SO}_{4}$ and let stand for 15 minutes and then separate the water and $\mathrm{Na}_{2} \mathrm{SO}_{4}$ in oil. Samples with \% yield of the largest in its chemical composition analysis using GCMS. Based on the results obtained the largest yield is $1.84 \%$ with content of eugenol is $65.03 \%$ and $20.94 \%$ trans-caryophyllene.
\end{abstract}

Key words : Clove leaf, Eugenol, Essential Oil, Steam distillation 


\section{Pendahuluan}

Minyak atsiri merupakan salah satu produk yang dibutuhkan pada berbagai industri seperti industri kosmetik, obatobatan, makanan dan minuman. Minyak atsiri juga dapat digunakan sebagai aroma terapi (Nurdjannah, 2004).

Daun cengkeh merupakan hasil dari pohon cengkeh yang belum banyak dimanfaatkan oleh petani dibandingkan dengan bunga atau tangkai cengkeh yang banyak digunakan untuk industri rokok dan makanan. Menurut Guenther tanaman cengkeh yang berumur lebih dari 20 tahun,setiap minggunya dapat terkumpul daun kering sebanyak rata-rata 0,96 $\mathrm{kg} /$ pohon,sedangkan tanaman yang berumur kurang dari 20 tahun dapat terkumpul sebanyak 0,46 kg/pohon (Supriatna dkk., 2004). Daun cengkeh yang mengandung minyak 1-4\%, sehingga dapat ekstraksi menjadi minyak atsiri yang bernilai ekonomis tinggi.

Isolasi minyak atsiri dari daun cengkeh dapat menggunakan beberapa metode yaitu ekstraksi, penyulingan dengan air, penyulingan dengan uap dan penyulingan uap dan air yang masingmasing metode memiliki kelebihan dan kelemahannya.

Menurut Sediawan (2000), Proses leaching (ekstraksi padat-cair) dapat digunakan untuk pengambilan minyak atsiri. Industri kecil umumnya masih belum bisa menggunakan teknologi ini karena keberhasilan proses ini sangat ditentukan oleh pengambilan kembali (recovery) solven, yang membutuhkan peralatan yang relatif baik. Harga solven biasanya relatif mahal, sehingga kehilangan solven akan sangat merugikan. Kelemahan lain adalah adanya sedikit solven yang tertinggal dalam produk. Untuk produk-produk tertentu, terutama bahan makanan, adanya sedikit solven tersisa tersebut perlu dihindari.

Isolasi minyak atsiri dapat menggunakan penyulingan dengan air. Menurut Hendartomo (2005), pada metode ini tanaman yang akan disuling dimasukkan dalam ketel dan kontak langsung dengan air mendidih. Bahan dapat mengapung di atas air atau terendam secara sempurna, tergantung pada berat dan jumlah bahan yang akan disuling. Ciri khas model ini yaitu adanya kontak langsung antara bahan dan air mendidih. Penyulingan dengan air sering disebut penyulingan langsung.

Minyak atsiri juga dapat diperoleh menggunakan metode penyulingan dengan uap. Hendartomo (2005) menyatakan model ini menggunakan uap yang dihasilkan dari boiler yang dialirkan dalam ketel yang berisi tanaman penghasil minyak atsiri model ini disebut penyulingan tak langsung. Kelebihan model ini dapat menggunakan beberapa ketel yang dipasang seri dalam satu boiler, sehingga produksi yang dihasilkan akan lebih besar. kelemahan dari proses ini adalah membutuhkan dana yang cukup besar karena adanya penambahan konstruksi boiler

Metode lain adalah penyulingan uap dan air. Menurut Hendartomo (2005), pada penyulingan ini, bahan tanaman yang akan disuling diletakan dalam penyangga berlubang, kemudian di isi dengan air sampai permukaannya tidak jauh bagian bawah saringan. Ciri khas model ini yaitu uap selalu dalam keadaan basah, jenuh, dan tidak terlalu panas. Bahan tanaman yang akan disuling hanya berhubungan dengan uap dan tidak dengan air panas.

Menurut LeFevre (1998) Secara umum fraksinasi destilasi merupakan terbawanya keluar campuran yang saling larut (miscible). Dengan mengasumsikan campuran tersebut ideal maka tekanan total uap pada sistem dapat didekati dengan menggunakan Hukum Roult yaitu:

$\mathrm{P}_{\mathrm{T}}=\mathrm{Po}_{1} \mathrm{X}_{1}+\mathrm{P}_{2} \mathrm{X}_{2}$

Fraksinasi terjadi pada campuran yang tidak saling larut (immiscible) disebut codistillation, jika salah satu zat tersebut berupa air ,maka proses ini disebut steam destillation/penyulingan uap. Kondisi dimana suatu bahan tidak saling larut tekanan total dapat dicari dengan Hukum Dalton yaitu:

$\mathrm{P}_{\mathrm{T}}=\mathrm{Po}_{1}+\mathrm{Po}_{2}$

Menurut Nurdjannah (2004) pohon cengkeh memiliki bau yang khas berasal dari minyak atsiri yang terdapat bunga $(10-20 \%)$, tangkai (5-10\%) dan daun (1-4\%). Komponen terbesar yang terdapat dalam minyak atsiri cengkeh adalah eugenol sebesar 70-80\%. Nurdjannah dkk. (1991) melakukan penyulingan daun cengkeh dalam tangki stainless steel volume $100 \mathrm{l}$ selama dalam delapan jam menghasilkan rendemen $3,5 \%$ dengan total eugenol $76,8 \%$. 
Penelitian yang telah dilakukan oleh Alma dkk. (2007) komposisi kimia minyak atsiri bunga cengkeh dari turki melalui proses penyulingan uap didapat komponen terbesar adalah $87 \%$ eugenol, 8,01 \% eugenyl asetat dan 3,56\% $\beta$-caryophyllene. Jirovetz dkk. (2006) menganalisa komposisi kimia dalam minyak daun cengkeh menggunakan GC dan GCMS didapat 23 komposisi kimia dengan kadar komponen terbesar adalah eugenol (76.8\%), followed by $\beta$-caryophyllene $\quad(17.4 \%), \quad \mathrm{R}$-humulene (2.1\%), and eugenylacetate (1.2\%).

Penelitian ini menggunakan metode penyulingan uap, diharapkan penggunaan uap lewat jenuh dengan tekanan uap yang divariasikan dan dikontakkan dengan daun cengkeh dapat memaksimalkan pengambilan minyak dari daun cengkeh. Analisa GCMS digunakan untuk mengetahui kulitas minyak daun cengkeh.

Tujuan penelitian ini adalah untuk mengetahui komposisi yang terkandung dalam minyak daun cengkeh hasil dari penyulingan uap menggunakan GCMS.

\section{Metodologi}

\section{Alat dan Bahan}

Bahan yang digunakan dalam penelitian ini daun cengkeh yang berasal dari daerah Purwakarta. Daun cengkeh didapat dari petani yang dikumpulkan dari daun cengkeh yang jatuh dari pohonnya.

Peralatan yang digunakan adalah satu set penyulingan uap yang terdiri dari boiler, ketel penyulingan, kondenser, pompa dan penampung sampel. Analisa komponen penyusun minyak atsiri daun cengkeh dilakukan di Laboratorium Kimia Organik MIPA UGM dan alat yang digunakan adalah GCMS QP2010S SHIMADZU dengan kolom Rastek RXi-5MS.

\section{Prosedur Penelitian}

Daun cengkeh kering seberat 1,5 kg yang sudah bersih dari kotoran dimasukkan dalam ketel suling dan ditutup dengan rapat. Steam dari boiler dialirkan ke ketel suling dengan tekanan 0,5 barG, 1 barG dan 1,5 barG selama 5, 6 dan 7 jam. Cairan yang keluar dari condenser diamkan selama 24 jam untuk memisahkan air dan minyak. Pada tahap pemurnian minyak daun cengkeh menggunakan metode yang telah dilakukan oleh Marwati dkk. (2005), minyak daun cengkeh dimurnikan dengan bentonit 10\% dari berat minyak pada suhu $50^{\circ} \mathrm{C}$ sambil diaduk selama 1 jam. Minyak daun cengkeh yang telah terpisah dari bentonit ditambahkan $\mathrm{Na}_{2} \mathrm{SO}_{4}$ anhidrat dan diamkan selama 15 menit kemudian pisahkan air dan $\mathrm{Na}_{2} \mathrm{SO}_{4}$ dalam minyak. Minyak daun cengkeh yang diperoleh dihitung $\%$ rendemennya. Sampel dengan rendemen terbesar dianalisa menggunakan GCMS. QP.2010S SHIMADZU dengan kolom Rastek RXi-5MS untuk mengetahui komposisinya. Rangkaian alat penelitian dapat dilihat pada Gambar 1.

\section{Analisis Komposisi Kimia Penyusun Minyak Atsiri Daun Cengkeh}

Peralatan yang digunakan adalah GCMS QP2010S SHIMADZU dengan kolom Rastek RXi-5MS dengan panjang $30 \mathrm{~m}$ dan diameter 0,25 mm. Kondisi kolom diatur dengan Suhu awal $100^{\circ} \mathrm{C}$, waktu awal 5 menit, Kenaikan suhu sebesar $5^{\circ} \mathrm{C} /$ menit dan Suhu akhir adalah $280^{\circ} \mathrm{C}$. Jenis detector adalah FTD dengan temperatur injector adalah $290^{\circ} \mathrm{C}$. Gas pembawa adalah Helium (He) dengan kecepatan alira 0,5 ml/menit dan tekanan : 22,0 kPa. Penentuan struktur senyawa dilakukan dengan menggunakan standar yang sudah diketahui dengan mencocokkan fragmentasi senyawanya. Setiap puncak yang muncul dalam kromatogram memiliki waktu retensi yang berbeda-beda.

\section{Hasil Dan Pembahasan}

\section{Pengaruh Tekanan SteamTerhadap Persen Rendemen}

Berdasarkan hasil penelitian yang telah dilakukan tekanan steam dan waktu penyulingan berpengaruh pada hasil minyak yang didapat. Tekanan penyulingan menyatakan laju alir steam dari boiler ke ketel penyulingan yaitu ketika pengukur tekanan pada boiler menunjukkan tekanan 0,5 barG, 1 barG atau 1,5 barG, maka valve 2 pada Gambar 1 dibuka steam akan mengalir dari boiler ke ketel penyulingan. Semakin tinggi tekanan steam, maka semakin besar laju alir steam ke ketel penyulingan. Gambar 2 berikut ini adalah \% rendemen minyak daun cengkeh yang diperoleh berdasarkan perbedaan tekanan steamnya.

Pada Gambar 2 dapat dilihat perbedaan rendemen minyak cengkeh akibat lama penyulingan yang berbeda, dari 


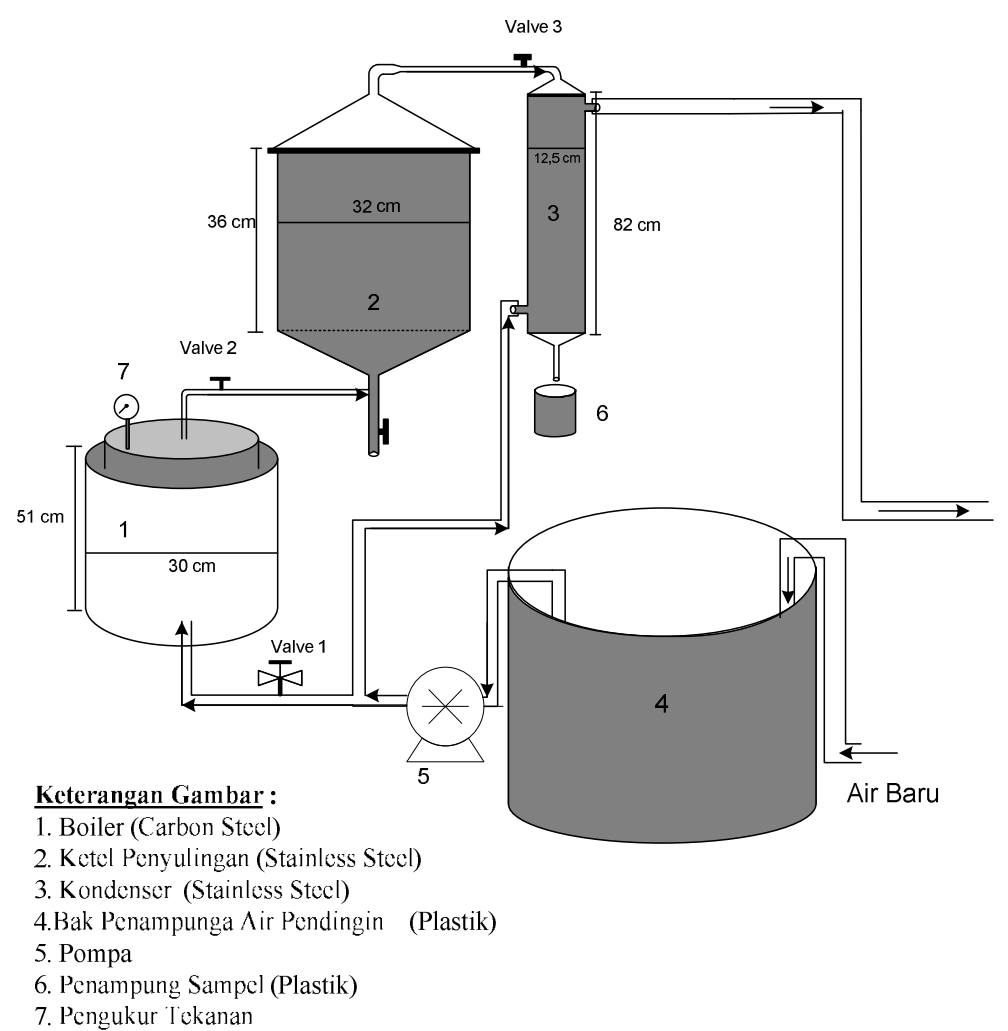

Gambar 1. Rangkaian Alat Penyulingan Uap

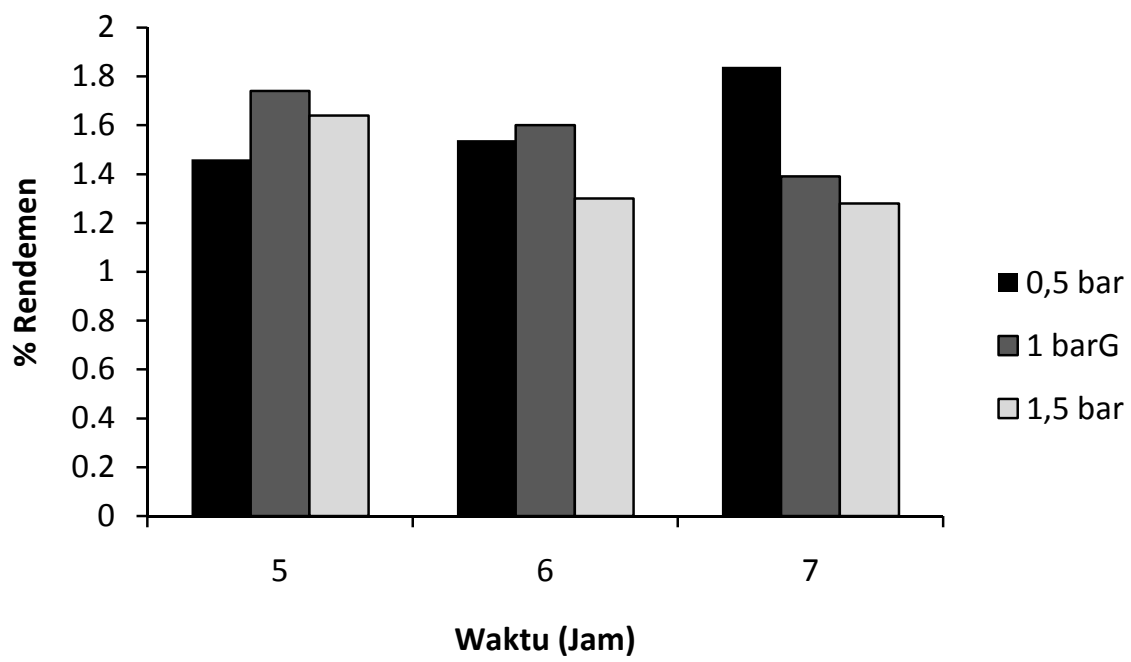

Gambar 2. Pengaruh Tekanan Steam Terhadap \% Rendemen

perlakuan tersebut dapat dilihat rendemen minyak berkisar antara $1.2-1,84 \%$. Hal ini berarti minyak cengkeh yang diperoleh sesuai dengan literatur yaitu $1-4 \%$ (Nurdjannah, 2004).

Pada Gambar 2 menunjukkan \% rendeman terbesar didapat pada tekanan 0,5 barG dengan waktu 7 jam yaitu sebesar 1,84
$\%$. Hal ini berkaitan dengan distribusi steam pada ketel yang mempengaruhi remdemen yang dihasilkan. Menurut Ginting (2004) semakin tinggi tekanan uap maka jumlah minyak per $\mathrm{kg}$ kondensat uap rendah, sehingga \% rendemen yang dihasilkan semakin rendah. Semakin tinggi tekanan uap semakin cepat aliran uap yang masuk dalam 
ketel suling sehingga kontak antara uap air dengan daun cengkeh menjadi singkat, akibatnya minyak atsiri yang terikat oleh uap air semakin sedikit. Penurunan tekanan uap air membuat laju aliran uap air yang masuk kedalam ketel menjadi lambat, sehingga kontak antara uap air dengan daun cengkeh menjadi lebih lama dan \% rendemen yang dihasilkan lebih besar.

Minyak atsiri merupakan salah satu hasil sisa dari proses metabolisme dalam tanaman yang terbentuk karena reaksi berbagai persenyawaan kimia dengan adanya air. Minyak tersebut disintesa dalam sel glandular pada jaringan (Ketaren, 1981). Destilasi uap merupakan proses kontak langsung antara steam dengan tanaman penghasil minyak atsiri. Minyak cengkeh dan air bersifat immiscible, maka kedua zat tersebut akan mendidih bersama pada suhu yang lebih rendah dari titik didih minyak cengkeh dan air. Uap yang terbentuk diembunkan sehingga terbentuk dua cairan yaitu air dan minyak cengkeh yang sulit dipisahkan dan mudah dipisahkan.

\section{Analisa Komposisi Kimia Minyak Daun Cengkeh Dengan GCMS}

Pada Gambar 3 dibawah ini dapat dilihat hasil analisa minyak daun cengkeh menggunakan GCMS. QP.2010S. SHIMADZU. Komposisi kimia yang terdapat pada minyak daun cengkeh dapat dilihat pada Gambar 3.

Sampel yang diuji dengan menggunakan instrumen gas chromatografi mass-spectrometri adalah pada variabel tekanan 0.5 barG dengan waktu 7 jam karena memiliki \% rendemen terbesar. Hasil analisa GCMS komponen terbesar adalah eugenol sebesar $65.03 \%$, trans-caryophyllene $20.94 \%$ dan $\alpha$-Humulene sebesar $3,04 \%$. Berdasarkan Standar Nasional Indonesia (SNI, 2006), minyak daun cengkeh

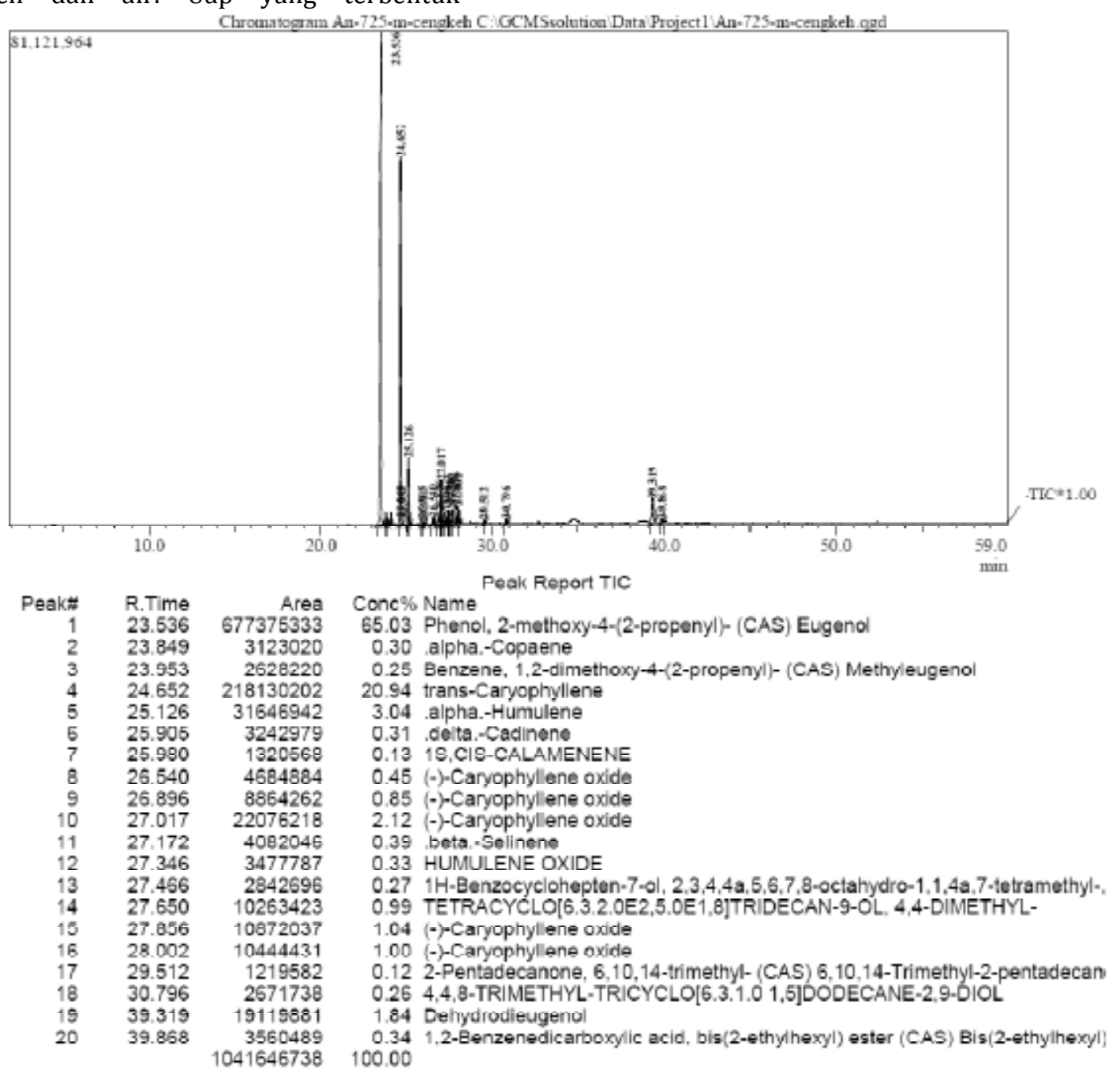

Gambar 3. Hasil Analisa Minyak Daun Cengkeh Menggunakan GCMS 
mempunyai kadar eugenol minimal 78\% dan beta-caryophyllene min $17 \%$ (SNI, 2006). Penelitian yang dilakukan oleh Jirovetz dkk. (2009) yang menganalisa komponen yang terkandung minyak atsiri daun cengkeh menggunakan penyulingan uap didapat 23 komponen dengan kadar tertinggi yaitu eugenol $76.8 \%, \beta$-caryophyllene $17.4 \%, \alpha$ humulene $(2.1 \%)$, dan eugenyl acetate $1.2 \%$. Rendahnya kadar eugenol terjadi karena sistem pendinginan dan penampungan sampel yang tidak sempurna, sehingga banyak eugenol yang menguap.

\section{Kesimpulan}

Berdasarkan hasil penelitian yang telah dilakukan, diperoleh \% rendemen terbesar yaitu 1,84\% pada Tekanan 0,5 barG selama 7 jam dengan komponen terbesar yaitu eugenol sebesar $65.03 \%$ dan transcaryophyllene $20.94 \%$.

\section{Daftar Pustaka}

Alma, M.H.; Ertas M.; Nitz S.; Kollmannsberger $\mathrm{H}$., Chemical composition and content of essential oil from the bud of cultivated turkish clove, BioResources, 2007, Vol. 2(2), 265-269.

Ginting, S., Pengaruh Lama Penyulingan Terhadap Rendemen Dan Mutu Minyak Atsiri Daun Sereh Wangi, Fakultas Pertanian, Universitas Sumatera Utara, 2004, http://repository.usu.ac.id/bitstream/12345 6789/788/1/tekper-sentosa.pdf, (diakses 2009).

Hendartomo, Pengambilan Minyak Atsiri Dari Daun dan Ranting Nilam (posgostemon Cablin benth) Dengan Cara Penyulingan Uap, 2005, http://minyakatsiriindonesia.wordpress.com /atsiri-nilam/hendartomo, (diakses 2008).
Jirovetz, L.; Buchbauer, G.; Stoilova, I.; Stoyanova, A.; Krastanov, A.; Schmidt, E., Chemical Composition and Antioxidant Properties of Clove Leaf Essential Oil, Journal of Agricultural and Food Chemistry, 2006, Vol. 54(17), 6303-6307.

Ketaren, S., Pengantar Teknologi Minyak Atsiri, Balai Pustaka. Jakarta, 1981.

Marwati, T.; Rusli, M.S., Noor, E.; Mulyono, E., Peningkatan mutu minyak daun cengkeh melalui proses pemurnian. Jurnal Penelitian Pascapanen Pertanian, 2005, Vol. 2(2), 45-52.

LeFevre, W., Isolating Clove Oil From Cloves Using Steam Distillation, Modular Laboratory Program in Chemistry, Chemical Education Resources Inc., USA, 1998, http://www.cerlabs.com/experiments/1087 5407226.pdf, (diakses 2008).

Nurdjannah, N., Diversifikasi Penggunaan Cengkeh, Perspektif, 2004, Vol. 3(2), 61-70.

Nurdjannah, N.; Hardja, S.; Mirna, Distillation method influence the yield and quality of clove leaf oil, Industrial Crops Research Journal. 1991, Vol. 3 (2), 18-26.

Sediawan, W. B., Berbagai Teknologi Proses Pemisahan, Prosiding Presentasi Ilmiah Daur Bahan Bakar Nuklir V P2TBDU dan P2BGNBATAN Jakarta, Jakarta, 22 Februari 2000.

Supriatna, A.; Rambitan, U.N.; Sumangat, D.; Nurdjannah, N., Analisis Sistem Perencanaan Model Pengembangan Agroindustri Minyak Daun Cengkeh : Studi kasus di Sulawesi Utara, Buletin TRO, 2004, Vol. XV(1), 1-18.

Standar Nasional Indonesia, Minyak Daun Cengkeh, SNI 06-2387-2006, 2006. 